\title{
Constructing Teacher-student Relationship Mechanism for EFL Development Based on Ubiquitous Computing Technologies
}

\author{
Huanhuan Ren ${ }^{1, a}$, Chi Ma ${ }^{2, b}$ \\ ${ }^{1}$ Teachign and Research Institute of Foreign Languages, Bohai University, Jinzhou 121013, China; \\ ${ }^{2}$ Jinzhou Institute of Forestry Research, Jinzhou Forestry Bureau, Jinzhou 121013, China. \\ arenhuanhuan2014@163.com, 'bmachi2014@tom.com
}

Keywords: Teacher-student relationship mechanism, EFL developments, ubiquitous computing technologies

\begin{abstract}
The advent and advance of ubiquitous computing technologies can be seen to have considerable implications for education, and the teacher-student relationship is influenced by the deployment of technologies. It's shown that enabling technologies create equity and freedom of access to digital resources and reduce the digital divide in ubiquitous learning. It's also argued that there are significant relationships between the teacher and the student as co-workers, consulting agents, close friends and key stakeholders, and much endeavor should be put in to foster EFL development through leveraging various dimensions of the teacher-student relationship in ubiquitous learning.
\end{abstract}

\section{Introduction}

Ubiquitous computing technologies provide the opportunity to transform teaching now more than ever before, and the teacher-student relationship is influenced by the deployment of state-of-the-art technologies. In a broad sense, this paper seeks to examine technological revolutions in ubiquitous learning, from e-learning, m-learning to u-learning, and main elements of teacher-student relationship in ubiquitous learning space. It sets out to demonstrate the influence enabling technologies can have on teacher-student relationship and analyze various dimensions of the teacher-student relationship in ubiquitous network environment. It's hoped that a deeper understanding of these issues may serve to promote pedagogy and EFL development in technology-rich school environments.

\section{The Technological Revolution in Teaching and Learning Setting}

Electronic Learning. As the telecommunications industry underwent swift changes in the 1980s, electronic learning (e-learning), in the short space of time between 1995 and 2000, became the state of the art for the use of technology in education[1]. Quite simply, electronic learning refers to any form of learning in which electronic technologies are utilized to support the learning process. For all e-learning means electronically supported learning (e.g. learning through the use of CD Rom also count as e-learning), the advent of the internet was the real catalyst for many important advances in e-learning[2]. There are some truth about the idea that the term is used to include the processes as computer based learning and internet based learning. E-learning features a whole raft of ideas for the tech-savvy learners and has been proven to be a successful method of learning. In spite that many people in the early days thought bringing computers into learning would remove that human element that some learners need[3], as time has progressed a number of universities worldwide are increasingly making positive attempts to implement e-learning strategies into educational curriculum.

Mobile Learning. The mobile revolution of the late 1990s makes wired technologies and applications beginning to be replaced by wireless ones[4], and it, in educational scenarios, will change the student from one who seeks for e-learning, to one who aspires for m-learning. Mobile 
learning (m-learning) refers to learning that takes place using small, portable handheld devices (such as iPods, cell phones, personal digital assistants, etc.) to allow the student to learn in different environments. It's found that m-learning is one of the latest developments in e-learning, taking advantage of mobile devices and wireless technology. In other words, mobile learning is, by its electronic nature, a subset of e-learning, but it refers to far more than e-learning. The term has grown enormously in popularity in the past few years, and it frees the learner who may have spent much time learning restricted to a classroom setting or tied to a desk. Learning can be achieved on accessible portable platforms whilst learners are on the move or far away from a regular computer. M-learning is therefore convenient, flexible, and in many cases cheaper than other forms of e-learning. It's shown that mobile learning is now firmly in place and beginning to take hold.

Ubiquitous Learning. Despite many predicting that e-learning was the final solution for autonomous learning and university programmers alike, the evidence is overwhelming that advances in technologies never stop here. As a researcher at Xerox PARC, Mark Weiser described in the late 80 s and the early 90s his vision for the next generation of computing, namely ubiquitous computing. As coined by him, ubiquitous computing refers to the process of seamlessly integrating computers into the physical world[5]. Ubiquitous computing leads to ubiquitous learning (u-learning) which is allowing to embed individual learning activities in everyday life. The goal is, that learning environments will be accessed increasingly in various contexts and situations. It's concluded that the main characteristics of ubiquitous learning are invisibility, accessibility and adaptability[6]. U-Learning has the potential to lead to an educational paradigm shift through removing many of the constraints in education, and it's expected to represent the next step in the field of m-learning. Currently, ubiquitous learning is performed in diverse educational settings and investigated in different directions.

\section{The Main Elements of Teacher-student (T-S) Relationships in Ubiquitous Learning Space}

The Equality of T-S Relationships in Ubiquitous Learning Space. Throughout the 20th century there were developments of the role of technology in learning, and its implications on teacher-student relationship is profound and far-reaching. The emergence and development of ubiquitous learning provides an opportunity to facilitate the equality in teacher-student relationship. In the past, the traditional EFL education emphasizes the idea that the students are inferior to the teachers and it gives the teachers and the students unequal status in the classroom. It's teachers who make informed decision about what to learn, and the only thing learners can do is to obey unconditionally without participation. The teacher is regarded the as the authority or the core of learning, while the student is in subordinate positions. Doors open as a large amount of just-in-time information can be accessed to by each autonomous learner at will through the magic of technology. Learners can also reach out for alternative avenues for communication such as instant messaging, ect. In a word, the equality in teacher-student relationship provides noticeable promise for transforming EFL education in ubiquitous learning space.

The Freedom of T-S Relationships in Ubiquitous Learning Space. One aspect of the teacher-student relationship worthy of notice within technology-rich environments is a certain freedom from constraints in traditional learning. Traditional face-to-face EFL courses only operate within normal office hours and occur in a fixed physical place. It may incur much inconvenience or even financial difficulties since traditional courses involve parking expenses, transportation fees, housing, or food service fees etc. As desktop computers are replaced by ubiquitous computing embedded in physical objects of everyday life, u-learning is less restrictive because it allows learning to occur anywhere and at anytime. U-learning is independent of the time and place and separates the learner not only from the teacher but also from the learning group. Through tapping the knowledge of experts beyond classroom wall, EFL learners can have augmented self-aware learning experience and freedom to direct the course of one's own life. It's conformed that the freedom in teacher-student relationship is more likely to result in an environment that allows a flexible learning opportunity in ubiquitous learning space. 


\section{Holistic Analysis of Teacher-student Relationship for EFL Development Based on Ubiquitous Computing Technologies}

The Relationship as Co-workers towards Common Mission. Although the relationship students form with their teachers can sometimes be complex and challenging, there is one thing for sure that they make decisions and take actions in view of the actualization of the same mission, namely the development of human being. Both of the student and the teacher play a dominant role in EFL teaching and learning setting but just in different directions. In this respect, the teacher and the learner are merely coworkers who are striking together to produce personal gains and make a difference in educational domain. Teachers are anticipated to draw students into the process of learning and promote their desire to learn so that learners can be in a better position to learn autonomously and fruitfully. Teachers are also supposed to create a positive and supportive climate in ubiquitous space to nurture learner autonomy which is an important means to achieve lifelong education. At the same time, EFL learners should put efforts and energies in learning activities to achieve at higher levels academically. It's obvious that this shared objective creates many expectations and sets in motion a dynamic and complex series of interactions. In a word, the student-teacher relationship as co-workers requires both learners and teachers to get to understand the value of mutual commitment to learning and foster collaboration between them through the better use of ubiquitous technology.

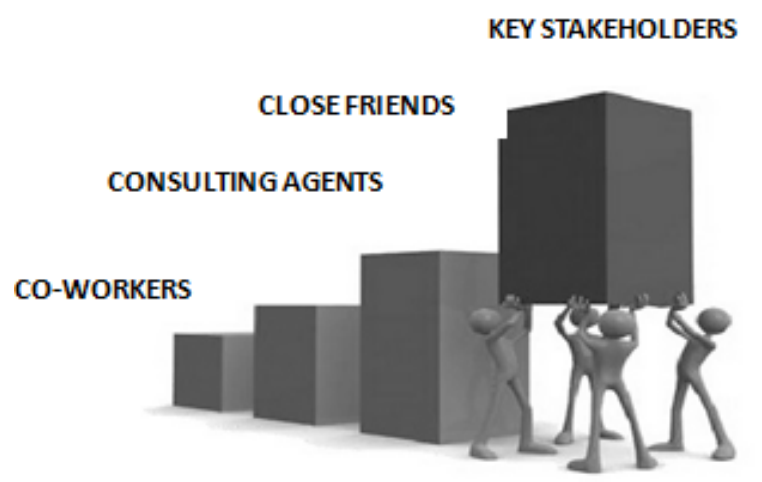

Fig. 1 Construction of teacher-student relationship mechanism

The Relationship as Consulting Agents towards Better Solution. Many things may come easily to learners but a successful EFL ubiquitous learning arrives after effort. Technology transforms knowledge, and makes new things possible in new ways. Ubiquitous learning is a process of more questions than answers, and teachers are deemed active councilors of learners providing suggestions about how to achieve easy learning outcomes whilst learners are delving into ubiquitous learning themselves. As for teachers, the evidence is overwhelming that technology has shaped the students that we teach in recent times, and today's students are no longer the people our traditional educational system was designed to teach. A certain amount of new unmet problems might pop up in instructional setting although an emerging body of literature has suggested that ubiquitous learning can deliver substantial positive effects. Hence, teachers have to resort to asking learners for ideas about what to provide in the upcoming learning stage, and at the same time pick out which techniques are best for which education scenario. The consultation from both sides should be delivered live through "electronically" raising your hand and interacting in real time. All in all, the relationship of consulting agents is embraced in ubiquitous learning so as to solve specific learning difficulties in EFL learning process.

The Relationship as Close Friends towards Deep Concern. The idea behind the student-teacher relationship as close friends is based on the promise that the social quality of human relationships contributes to both academic and social-emotional development. It's found that a healthy student-teacher interpersonal relationship not only provides learners the foundation for successful adaptation to the social and academic environment, but it's also beneficial to teachers through making teachers' job more efficient and more worthwhile. Hence teachers are required to treat learners the way they would like to be treated. Simply stated, learners and teachers should show 
warmth, respect and care toward each other. The rise of technology in the classroom makes this concern more convenient. As more educators make themselves accessible to students via social media and text messaging, more things covering learning needs, personal interests, etc, can be discovered and shared among them. It has to be noted that teachers focus not only on improving their relationships with students, but also on enhancing the relationships among EFL students. In a word, a good teacher-student relationship in ubiquitous learning space make classroom environments more conducive to learning and meet students' developmental, emotional and academic needs.

The Relationship as Key Stakeholders towards Mutual Development. When teachers and students interact as social members in ubiquitous learning system, one thing that can't be ignored is the teacher-student relationship as key stakeholders in educational field. The word "stakeholder" has gained wide acceptance and become more commonly used in business practice, however it also has educational implications. Learners and teachers are among the group of the same interest. Any action taken by teachers might affect their learners who are linked with them in the learning setting, and the teacher has an interest in the overall level of development of their students. It require one side of them to reflect and assess on the performance of the other and make a demand on them for future development. However, no easy and kind words are welcome in the process, and both the teacher and the learner should be responsible for themselves by being highly critical to each other. There seems to be universal agreement that critical thinking is one indispensable instrument of development and achievement in all fields of human endeavor including the ubiquitous learning field. In brief, the benefits of the teacher-student relationship as key stockholders is obvious and may accrue from being critically reviewing on one another's performance and development.

\section{Summary}

As computing technology seems to be trending towards the actualization of the original ubiquitous learning concepts as described by Mark Weiser, one thing that has to be noted is the teacher-student relationship for EFL development in ubiquitous learning space. Enabling technologies create equity and freedom of access to digital resources and reduce the digital divide. The major conclusion forwarded by this research is that there are significant relationships between the teacher and the student as co-workers, consulting agents, close friends and key stakeholders. The proposed future work is to foster EFL development through leveraging various dimensions of the teacher-student relationship in use of ubiquitous computing technologies.

\section{Acknowledgements}

This work is part of the project of On Cultivating and Developing Liaoning Scientific Foreign Language Talents with View to Bourdieu' Theory, the project of On Establishing Generative Mechanism of EFL Autonomous Learning Behaviors and Strengthening Development of Learning Field in Ubiquitous Learning Space, and the project of On Constructing Mechanism and Strategies for College English Autonomous Learning Abilities via Mobile Multimedia. This research was supported by the fund of Liaoning Planning of Philosophy and Social Science (Project No. L16CYY001), the fund of Liaoning Provincial Federation Social Science Circles (Project No. 2017lslktyb-019), and the fund of the Thirteenth Five-Year Plan of Education Sciences of Liaoning Province (Project No. JG16DB013).

\section{References}

[1][2][4] D. Keegan, The future of learning: From eLearning to mLearning, online. ZIFF Papiere 119, FernUniversitat - Hagen, 2002.

[3] L. Bates, The different uses of e-learning and m-learning, https://www.fractuslearning.com, 2016. 
[5] M. Weiser, The computer for the 21st century, Scientific American,1991, 265 (3).

[6] H.H. Ren, On establishing EFL teaching model to cultivate learner autonomy in ubiquitous network environment. 2nd International Conference on Future Computer Supported Education. Pennsylvania: DEStech Publications, Inc., 2015. 